\title{
Neuropsychiatric Involvement in Subclinical Hypothyroidism
}

\author{
Salem Bouomrani ${ }^{1,2 *}$ and Ines Masmoudi ${ }^{1,2}$ \\ ${ }^{1}$ Department of Internal Medicine, Tunisia \\ ${ }^{2}$ Sfax Faculty of Medicine, University of Sfax, Tunisia
}

*Corresponding author: Salem Bouomrani, Department of Internal medicine, Military Hospital of Gabes, Gabes 6000, Tunisia.

Received Date: April 06, 2020

Published Date: April 28, 2020

\begin{abstract}
s
Sub-clinical hypothyroidism (SCH), defined by an increase in thyroid stimulating hormone (TSH) with a normal free total thyroxin (fT4) fraction, is the most frequent thyroid dysfunction. Its average prevalence is estimated at $4-10.5 \%$, but can reach $15 \%$ in women over 50 years, and up to $20 \%$ in elderly beyond 60 years. Clinical manifestations during this endocrinopathy are not unanimous. Neuropsychiatric manifestations associated to $\mathrm{SCH}$ are far from uncommon; they significantly alter the quality of life of patients, may be the first signs revealing the disease, and present a real challenge for clinicians. Their better knowledge is very useful for any health professional given the high frequency of this disease in the general population. The objective of this review is to familiarize health professionals, in particular primary care physicians, with the different patterns of neuropsychiatric involvement of SCH.
\end{abstract}

Keywords: Sub-clinical hypothyroidism; Central nervous system; Peripheral nervous system; Neuropsychiatric involvement; Neuropathy; Hypothyroidism

\section{Introduction}

Sub-clinical thyroid dysfunctions (hypo- or hyper-thyroidism) are far more frequent than overt (clinically symptomatic) ones. These are biological entities characterized by abnormal blood thyroid stimulating hormone (TSH) levels with normal levels of circulating thyroid hormones (triiodothyronine (T3) and thyroxine (T4)). Sub-clinical hypothyroidism ( $\mathrm{SCH}$ ), defined by an increase in plasma TSH with a normal free total thyroxin (fT4) fraction, is the most frequent thyroid dysfunction [1,2]. Even if its average global frequency is estimated at $4-10.5 \%[3,4]$, SCH remains under-estimated. This is because it is often neglected and underdiagnosed; indeed $\mathrm{Li} \mathrm{H}$ et al in their systemic screening work for thyroid dysfunction in a population of healthy Chinese adults had found SCH in $14.7 \%$ versus overt hypothyroidism in 4\%, subclinical hyperthyroidism in $2.3 \%$, and overt hyperthyroidism in $1 \%$ [2]. It is particularly frequent in women [5] and the elderly, especially over 60 years [6]: 10 to $15 \%$ of women over 50 years [7], and up to $20 \%$ beyond 60 years old [3].

Clinical manifestations in connection with thyroid hormone deficiency are by definition absent [3,6,8,9]. However, there are some controversies as to the clinical presentation of this endocrinopathy since, contrary to certain authors who demand that the patient be asymptomatic, others affirm that SCH may include some signs or symptoms without as much provide a specific justification for the occurrence of these symptoms/signs [10,11]. Even the BillewiczZulewski scale which includes 12 clinical items (symptoms and signs) specific for the diagnosis of hypothyroidism with a binary rating for each $(0=a b s e n t$ and $1=$ present $)$ recognizes that a score between 3 and 5 can be seen during subclinical hypothyroidism [12].

This variability in possible clinical presentations of SCH can be explained by the existence of an individual "set-point" of TSH; generally determined by the hypothalamic-pituitary-thyroid axis $[13,14]$. The individual variability of this set-point could explain the different symptomatic spectra in subjects with the same TSH value [15].

\section{Clinical Impact of Subclinical Hypothyroidism}

The clinical repercussions of SCH are inconsistent, non-specific and non-discriminatory, making the actual clinical significance 
of SCHI very controversial [3]. Even excluding the classic signs and/or symptoms of hypothyroidism commonly validated by the Billewicz-Zulewski scale, namely periorbital edema, constipation, weight gain, hoarseness, skin cold, rough skin, dryness of the skin, paraesthesia, hearing loss, motor slowdown, decreased sweating and osteotendinous hyporeflexia [12], several other clinical manifestations, often at a minimum, can be found during the HIC; in particular cardiovascular [16-18], hepatobiliary [19,20], sexual, and neuropsychiatric. These repercussions may be direct or indirect, are especially observed if the TSH level is higher than $10 \mathrm{mIU} / \mathrm{l}$, and lead to a marked deterioration of the quality of life.

It should also be noted that the clinical expression is not strictly parallel to the biological abnormalities, explaining the existence of a clinical-biological dissociation which is often disturbing during SCH [21,22].

Neuropsychiatric impact of subclinical hypothyroidism. Thyroid hormones play a major role in the myelination, growth, maturation, and metabolism of both central and peripheral nervous systems [23].

SCH \& central nervous system. In the central nervous system, SCH is mainly associated with impaired cognitive functions $[6,24]$, memory disorders, especially verbal memory, and executive function disorders [24]; all of these disturbances are related to damage in the hippocampus [24].

The Aghili R et al work, studying the development of memory skills in patients with $\mathrm{SCH}$, showed a significant improvement in the memory quotient after hormone replacement therapy with levothyroxine. The Wechsler memory scale used for this assessment had increased by 9.3 points on average after treatment versus only 3.23 points on average in the control group receiving placebo; $p=0.002$ [25]. There was also a significant improvement in logical memory $(\mathrm{p}<0.001)$, mental control $(\mathrm{p}=0.002)$, and associated learning $(\mathrm{p}=0.014)$. The improvement in the memory quotient remained significant even after adjustment according to age subgroups $(\mathrm{p}<0.001)$ [25].

Yin JJ et al, in a recent and interesting study confirmed the clear deterioration of the memorizing faculties in SCH's patients compared to healthy euthyroid subjects. This alteration was evidenced by functional MRI objectifying a significantly lowered neuronal activity in the frontal cortex; more precisely the dorsolateral prefrontal cortex (DLPFC), and the posterior part of the right parietal lobe [26]. All of these anomalies were reversible after hormone replacement therapy leading to biological euthyroidism; the brain functional MRI controls after six months of treatment were identical to those in the healthy controls group. The same authors have, in a previous study, shown that verbal memory is significantly disturbed in SCH's patients with functional impairment of neurons in the frontal areas bilaterally [26]. Contrary to this work, the "Prosper" study: Prospective Study of Pravastatin in the Elderly at Risk, carried out on subjects aged over 70 years (70-82 years) did not objectify any significant contribution from
SCH in cognitive decline in the elderly [27]; but it should be noted that this study was done in patients who already had a pre-existing vascular disease or at least one cardiovascular risk factor and who received polymedication [27]. SCH also appears to be a risk factor for cerebral ischemic strokes: indeed 23 out of 165 patients admitted for recent ischemic stroke in the Wollenweber FA et al series had SCH (frequency=13.9\%) [28].

$\mathrm{SCH}$ is also now recognized as an exacerbating factor of migraine, just like overt hypothyroidism: the study by Fallah $\mathrm{R}$ et al, in 5 to 15 years old migraine children showed a higher frequency of attacks $(20.12 \pm 9.49$ Vs $14.74 \pm 8.9, p=0.04)$ as well as a longer average duration of attacks $(3.75 \pm 2.71 \mathrm{~h}$ Vs $1.96 \pm 1.08, \mathrm{p}=0.03)$ in migraine sufferers with SCH compared to euthyroid ones [29]. Because of these findings, the authors recommend screening for SCH in all migraine sufferers [29].

\section{SCH \& Peripheral Nervous System}

In the peripheral nervous system, asymptomatic neuropathy was found in $11 \%$ of cases on systematic examination of subjects with SCH; similarly, the skin biopsy systematically performed in these subjects had objectified a significant reduction of intraepidermal nerve fibers in $25 \%$ of cases [30].

\section{Psychiatric Impact Of SCH}

Psychiatric repercussions are very frequent during this endocrinopathy; however, they often remain under diagnosed by health professionals. Indeed, the work of Reuters VS et al using specific scores such as: the Hamilton Scale for Anxiety and Depression, the Beck questionnaire on depression and psychopathological symptoms in general (Beck Depression Inventory: BDL), the quality of life tests (Portuguese-Brazilian version of SF-36: Brasilian-Portuguese version of the Medical Outcomes Study 36-Items Short Form Health Survey) where among the items we find general condition, moral pain, emotional status, vitality and mental status, has documented the general psychological impact of SCH. The authors found more anxiety, depression, and emotional distress in SCH's subjects [31]. All of these symptoms had significantly improved after hormone replacement therapy normalizing TSH (comparative, randomized, double-blind study, levothyoxine versus placebo) [31].

\section{Skeletal Muscle Impact of SCH}

Although moderate and often insignificant elevations of muscle enzymes (CPK and LDH) are common during SCH [32-34], the symptomatic muscle impact of these endocrinopathy remains exceptional. Myopathy can result in myalgia or muscle stiffness but mainly it is intolerance to exercise as evidenced by hyperlactatemia, reduced oxygen consumption (VO2max), and increase in respiratory coefficient during exercise [35] as well as abnormally high intramuscular acidification at the end of exercise detected by phosphorus magnetic resonance spectrometry [36].

The electromyogram (EMG) remains conventionally unchanged during SCH [35] but a significant increase in repetitive discharges 
both at rest and after physical exercise or during ischemia can be detected by surface EMGs. These anomalies are the translation of a neuromuscular hyper-excitability which could result from a tendency to decrease of the extra cellular ionized calcium which characterizes SCH $[37,38]$.

All of these clinico-physiological anomalies are improved after hormone replacement therapy normalizing TSH [38].

\section{Conclusion}

Neuropsychiatric manifestations of subclinical hypothyroidism are far from uncommon; they significantly alter the quality of life of patients, and may be the first signs revealing the disease, and presenting a real challenge for clinicians. Their better knowledge is very useful for any healthcare professional, especially those in primay care given the high frequency of $\mathrm{SCH}$ in the general population. This knowledge will allow the early diagnosis of the disease, and the prompt treatment of the hormonal deficit. Screening for SCH is therefore recommended in front of any unexplained neuropsychiatric manifestation, in particular in women and the elderly.

\section{Acknowledgement}

None.

\section{Conflicts of Interest}

No conflicts of interest.

\section{References}

1. Marwaha RK, Tandon N, Ganie MA, Kanwar R, Sastry A, et al. (2012) Status of thyroid function in Indian adults: two decades after universal salt iodization. J Assoc Physicians India 60: 32-36.

2. Li H, Sang Z, Tan L, Zhao N, Wei W, et al. (2012) Thyroid function and serum lipids of adults living in areas of excessive iodine in water in Hebei province. Wei Sheng Yan Jiu 41: 536-9, 542.

3. Nakajima Y, Yamada M (2012) Subclinical thyroid disease. Nihon Rinsho 70: 1865-1871.

4. Biondi B, Cappola AR, Cooper DS (2019) Subclinical Hypothyroidism: A Review. JAMA 322(2): 153-160.

5. Fardella C, Poggi H, Gloger S, Rojas A, Velasquez CG, et al. (2001) High prevalence of subclinical thyroidal disease among individuals attended in health control. Rev Med Chil 129: 155-160.

6. Macedo Silva S, Carvalho A, Lopes-Pereira M, Fernandes V (2018) Subclinical Hypothyroidism on the Elderly. Acta Med Port 31(12): 766773.

7. Lamine F, De Giorgi S, Marino L, Michalaki M, Syki otis GP (2018) Subclinical hypothyroidism: new trials, old caveats. Hormones (Athens) 17(2): 231-236.

8. Franklyn J (2013) The Thyroid - too much and too little across the ages. The consequences of subclinical thyroid dysfunction. Clin Endocrinol (Oxf) 78(1): 1-8.

9. Biondi B (2012) Natural history, diagnosis and management of subclinical thyroid dysfunction. Best Pract Res Clin Endocrinol Metab 26: 431-446.

10. Ladenson PW, Singer PA, Ain KB, Bagchi N, Bigos ST, et al. (2000) American Thyroid Association guidelines for detection of thyroid dysfunction. Arch Intern Med 160: 1573-1576.
11. Klee GG, Hay ID (1997) Biochemical test of thyroid function. Endocrinol Metab Clin North Am 26: 763-775.

12. Zulewski H, Muller B, Exer P, Miserez AR, Miserez AR, et al. (1997) Estimation of tissue hypothyroidism by a new clinical score: evaluation of patients with various grades of hypothyroidism and controls. J Clin Endocrinol Metab 82: 771-776.

13. Andersen S, Pedersen KM, Bruun NH, Laurberg P (2002) Narrow individual variations in serum $\mathrm{T} 4$ and $\mathrm{T} 3$ in normal subjects: a clue to understanding of subclinical thyroid disease. J Clin Endocrinol Metab 87: 1068-1072.

14. Hansen PS, Brix TH, Sorensen TI, Kyvik KO, Hegedus L (2004) Major genetic influence on the regulation of the pituitary-thyroid axis: a study of healthy Danish twins. J Clin Endocrinol Metab 89: 1181-1187.

15. Fatourechi V (2009) Subclinical hypothyroidism: an update for primary care physicians. Mayo Clin Proc 84: 65-71.

16. Biondi B, Cooper DS (2008) The clinical significance of subclinical thyroid dysfunction. Endocrine Reviews 29: 76-131.

17. Hernández-Mijares A, Jover A, Bellod L, Bañuls C, Solá E, et al. (2013) Relation between lipoprotein subfractions and TSH levels in the cardiovascular risk among women with subclinical hypothyroidism. Clin Endocrinol (Oxf) 78: 777-782.

18. Bouomrani S, Ben Khalifa A (2020) Resistant Hypertension: Don't Forget Subclinical Hypothyroidism. EC Cardiology 7(3): 01-03.

19. Laukkarinen J, Sand J, Nordback I (2012) The underlying mechanisms: how hypothyroidism affects the formation of common bile duct stones-a review. HPB Surg: 102825.

20. Xu L, Ma H, Miao M, Li Y (2012) Impact of subclinical hypothyroidism on the development of non-alcoholic fatty liver disease: A prospective casecontrol study. J Hepatol 57: 1153-1154.

21. McDermott MT, Ridgway EC (2001) Subclinical hypothyroidism is mild thyroid failure and should be treated. J Clin Endocrinol Metab 86: 45854590 .

22. Surks MI, Goswami G, Daniels GH (2005) The thyrotropin reference range should remain unchanged. J Clin Endocrinol Metab 90: 5489-5496.

23. Smith JW, Evans AT, Costall B, Smythe JW (2002) Thyroid hormones, brain function and cognition: a brief review. Neurosci Biobehav Rev 26: 45-60.

24. Correia N, Mullally S, Cooke G, Tun TK, Phelan N, et al. (2009) Evidence for a specific defect in hippocampal memory in overt and subclinical hypothyroidism. J Clin Endocrinol Metab 94: 3789-3797.

25. Aghili R, Khamseh ME, Malek M, Hadian A, Baradaran HR, et al. (2012) Changes of subtests of Wechsler Memory Scale and cognitive function in subjects with subclinical hypothyroidism following treatment with levothyroxine. Arch Med Sci 8: 1096-10101.

26. Yin JJ, Liao LM, Luo DX, Xu K, Ma SH, et al. (2013) Spatial Working Memory Impairment in Subclinical Hypothyroidism: An fMRI Study. Neuroendocrinology 97(3): 260-270.

27. Wijsman LW, de Craen AJ, Trompet S, Gussekloo J, Stott DJ, Rodondi N, et al. (2013) Subclinical thyroid dysfunction and cognitive decline in old age. PLoS One 8: e59199.

28. Wollenweber FA, Zietemann V, Gschwendtner A, Opherk C, Dichgans M (2013) Subclinical hyperthyroidism is a risk factor for poor functional outcome after ischemic stroke. Stroke 44: 1446-1448.

29. Fallah R, Mirouliaei M, Bashardoost N, Partovee M (2012) Frequency of subclinical hypothyroidism in 5- to 15-year-old children with migraine headache. J Pediatr Endocrinol Metab 25: 859-862.

30. Magri F, Buonocore M, Camera A, Capelli V, Oliviero A, et al. (2013) Improvement of intra-epidermal nerve fiber density in hypothyroidism after L-thyroxine therapy. Clin Endocrinol (Oxf) 78(1): 152-153. 
31. Reuters VS, Almeida P, Teixeira F, Vigário Pdos S, Ferreira MM, et al. (2012) Effects of subclinical hypothyroidism treatment on psychiatric symptoms, muscular complaints, and quality of life. Arq Bras Endocrinol Metabol 56: 128-136.

32. Beyer IW, Karmali R, Demeester-Mirkine N, Cogan E, Fuss MJ (1998) Serum creatine kinase levels in overt and subclinical hypothyroidism. Thyroid 8: 1029-1031.

33. Hekimsoy Z, Oktem IK (2005) Serum creatine kinase levels in overt and subclinical hypothyroidism. Endocr Res 31: 171-175.

34. McGrowder DA, Fraser YP, Gordon L, Crawford TV, Rawlins JM (2011) Serum creatine kinase and lactate dehydrogenase activities in patients with thyroid disorders. Niger J Clin Pract 14: 454-459.

35. Caraccio N, Natali A, Sironi A, Baldi S, Frascerra S, et al. (2005) Muscle metabolism and exercise tolerance in subclinical hypothyroidism: a controlled trial of levothyroxine. J Clin Endocrinol Metab 90: 4057-4062.
36. Kaminsky P, Robin-Lherbier B, Brunotte F, Escanye JM, Walker P, et al. (1992) Energetic metabolism in hypothyroid skeletal muscle, as studied by phosphorus magnetic resonance spectroscopy. J Clin Endocrinol Metab 74: 124-129.

37. Monzani F, Caraccio N, Siciliano G, Manca L, Murri L, et al. (1997) Clinical and biochemical features of muscle dysfunction in subclinical hypothyroidism. J Clin Endocrinol Metab 82: 3315-3318.

38. Monzani F, Caraccio N, Del Guerra P, Casolaro A, Ferrannini E (1999) Neuromuscular symptoms and dysfunction in subclinical hypothyroid patients: beneficial effect of L-T4 replacement therapy. Clin Endocrinol (Oxf) 51: 237-242. 